\title{
Hedonics Act in Unison with the Homeostatic System to Unconsciously Control Body Weight
}

\author{
Heike Münzberg, Emily Qualls-Creekmore, Sangho Yu, Christopher D. Morrison and \\ Hans-Rudolf Berthoud* \\ Pennington Biomedical Research Center, Louisiana State University System, Baton Rouge, LA, USA
}

Keywords: obesity, body weight, eating behavior, brain, food reward, palatability, cognitive control, decision-making

\section{INTRODUCTION}

With the global obesity crisis continuing to take its toll, the demand for solutions has increased. The discussion about nature vs. nurture and biology vs. psychology has culminated in declaring obesity as a disease by some medical organizations. Environmental factors and genetic predisposition, rather than personal responsibility are to blame, as for any other disease. This view implies that the biological processes regulating body weight are essentially operating at the unconscious realm. Although this has long been accepted for the so-called homeostatic regulation of energy balance, it is less clear for the hedonic controls. Here, we critically evaluate the important question how rodent models can help understand the contribution of hedonic neural processes to body weight regulation. When looking at the concepts of reward, reinforcement, motivation, pleasure addiction, and their neural mechanisms, in the context of eating and exercise, the new view emerges that homeostatic and hedonic controls are closely interrelated and often act in unison at the unconscious level to achieve biologically adaptive responses. Although the discussion of a body weight set point has been neglected in recent years, this topic becomes more pressing as an important aspect for effective treatment of obesity.

\section{HEDONIC MECHANISMS OVERPOWER HOMEOSTATIC REGULATION}

When the body weight of animals and humans is disturbed by periods of either under- or overfeeding, it promptly returns to pre-perturbation levels through a process termed homeostatic regulation that involves the controls of both energy intake and energy expenditure $(1,2)$. The basic hypothalamic circuitry underlying this regulation has long been known (3) and was much refined, particularly over the last 20 years in the wake of the discovery of leptin. In brief, two distinct neural populations in the mediobasal hypothalamus act as primary energy sensors and engage a complex network of effector circuits controlling both energy-in and energy-out in a biologically adaptive fashion [for review, see Ref. (4-7)].

However, while most agree with such basic homeostatic regulation, there has been much discussion regarding the exact level of defended body weight and the mechanisms involved $(8-13)$. Clearly, there is no fixed set point around which mammalian species regulate their body weight. Rather, it is flexible, depending on both internal and external conditions including genetic and epigenetic predisposition, food availability, food palatability, and other 
environmental factors (10). This is best illustrated by the seasonably variable and homeostatically defended body weight set point of hibernators (14).

One factor that is widely believed to be very important for influencing the individual body weight set point is food hedonics, particularly the shift toward higher body weight by highly palatable, calorie-dense foods (Figure 1A). The clearest example of this shift in defended body weight is the cafeteria diet-induced obese rat and mouse (15). Although it is suspected that the increased availability of highly palatable, energy-dense foods is also mostly responsible for the current obesity epidemic, it is much harder to prove, because of difficulties to strictly control energy balance and environmental conditions in humans over extended periods of time as it is possible in animal models. A widely accepted view is that in genetically and/or epigenetically susceptible individuals, the obesogenic food environment is able to establish a new, higher body weight set point that is similarly defended against forced fasting and overfeeding as in normal weight individuals (11). Therefore, one of the key issues in understanding body weight regulation is the neurological explanation for this shift in defended body weight. What are the neural mechanisms that allow availability and palatability of energy-dense foods to overpower the basic homeostatic defense system? Understanding these mechanisms could lead to the development of more specific drugs or behavioral interventions in the fight against obesity.

\section{HEDONIC PROCESSING IS AN INTEGRAL PART OF THE HOMEOSTATIC REGULATORY SYSTEM}

The view that the hedonic and homeostatic neural circuitries are not separate entities but are part of the same regulatory system is rapidly gaining traction. This is based on evidence for bidirectional modulation of corticolimbic brain areas by interoceptive signals, and of the hypothalamus by exteroceptive signals and their cognitive and emotional correlates (Figure 1B).

\section{Bottom-up Modulation of Corticolimbic Circuits of Cognition and Motivation by Interoceptive Signals of Nutrient Availability}

The bottom-up control of hedonic and cognitive processes by internal signals is not a new insight. Given the crucial importance of nutrients for survival, it is a fundamental attribute of the expression of hunger and goes back to the beginning of evolution of the nervous system. Specifically, the hungry state is characterized by increased incentive salience attribution (the mechanism by which a goal object such as food is becoming highly desired and wanted - a behavioral magnet), which is neurologically manifested by heightened activity of the mesolimbic dopamine system (16-18). What is new, are some of the messengers and neural mechanisms shown to be involved. For example, it is now clear that one of the most eminent homeostatic regulators of body weight - leptin - modulates appetite by acting not only on the hypothalamus but also on components of the mesolimbic dopamine system (19-22) and on olfactory and taste sensory processing (23-25). Similarly, many other internal signals of nutrient availability, such as ghrelin, intestinal GLP-1 and PYY, and insulin, as well as glucose and fat, also partly act on corticolimbic structures involved in the cognitive and rewarding aspects of food intake control (26-36). Effects on cognitive functions by these hormones are interesting in the context of human studies showing impairments of both cognitive and metabolic functions in obese patients (37-39). Although the common link is not yet known, a leading hypothesis suggest that intestinal dysbiosis resulting from an interaction between sub-optimal nutrition, gut microbiota, and the innate immune system with subsequent changes in gut-to-brain signaling and blood-brain barrier integrity are important (40-43).
A Homeostatic-Hedonic Dichotomy Model

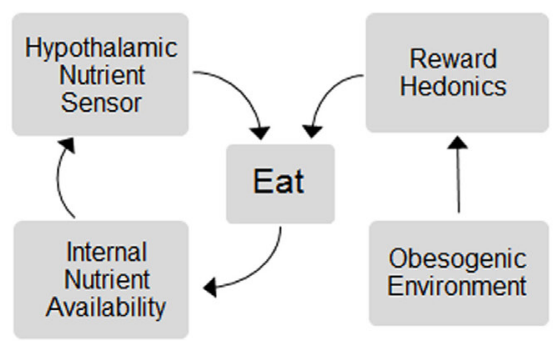

B Integrative Model

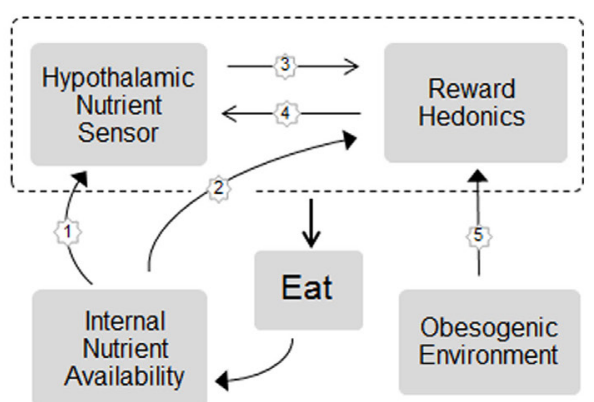

FIGURE 1 | Schematic representation of the (A) dichotomy and (B) integrative models of homeostatic and hedonic control of food intake and regulation of body weight. In the dichotomy model, homeostatic and hedonic mechanisms are largely independent. In the integrative model, the neural circuitries for internal nutrient sensing and hedonic processing act in concert to control eating and body weight and the hedonic system becomes part of the homeostatic system. Signals of both short- and long-term internal nutrient availability, such as leptin, gut hormones, and metabolites, are sensed by both, the hypothalamic nutrient sensor (pathway 1) and hedonic/reward processing centers (2), and these circuits communicate bidirectionally with each other (3 and 4) to unconsciously affect eating. For simplicity, energy expenditure as effector mechanism in the regulation of body weight is not included. For details, see text. 


\section{Top-down Modulation of the Classical Hypothalamic Regulator by Sensory, Cognitive, and Motivational Signals}

The other driver of this integrated view is new insight into the top-down modulation of classical homeostatic circuitries by cognitive and emotional processing in corticolimbic systems (44). Cue-induced, conditioned food intake is thought to be an important mechanism in overeating by humans in an obesogenic environment $(45,46)$ and has been studied in rodents for quite some time (47). Some of the relevant pathways involved in this cognition-dependent food intake have been identified in the rat by demonstrating dependence on amygdala and prefrontal cortex-to-lateral hypothalamus projections $(48,49)$. Most recently, evidence for top-down modulation of AGRP neurons in the mediobasal hypothalamus, the epicenter of classical homeostatic regulation, was presented. These powerful neurons have been thought to be mainly controlled by circulating hormones and metabolites in a relatively slow waxing and waning fashion commensurate with the fasted and fed states. Using modern, genetically based neuron-specific technology, it was demonstrated that activity of AGRP neurons is also controlled on a second-by-second basis by the conditioned expectation of imminent food ingestion $(50,51)$. This acute external sensory and cognitive control over AGRP neuron firing rate is likely accomplished by direct or indirect inputs from a number of cortical and subcortical areas as demonstrated by neuron-specific retrograde viral tracing (52).

\section{CONTROL OF FOOD INTAKE AND REGULATION OF ENERGY BALANCE IS PREDOMINANTLY SUBCONSCIOUS}

It is clear that the classical hypothalamic neural circuitry responsible for the homeostatic regulation of energy balance and body weight, similar to homeostatic regulation of other bodily functions, such as blood glucose or blood pressure, is operating largely beyond awareness, at the unconscious level. In addition and as discussed above, the incentive sensitization mechanism by which interoceptive signals of energy depletion such as low leptin drive "wanting" through the mesolimbic dopamine system $(16,18,53)$ is also largely operating outside awareness as demonstrated in human neuroimaging studies (54-56). Even in the absence of metabolic hunger and associated interoceptive sensitization signals, conscious awareness of the cue does not seem necessary. This has been shown in rats with cue-induced conditioned food intake $(47,48)$. Furthermore, the human brain can learn the value of monetary rewards and use it for decision-making without conscious processing of contextual cues (57). Although optimal decision-making requires selfcontrol, represented in the dorsolateral prefrontal cortex $(58,59)$, the transformation of reward-driven behavioral action is not under obligatory control of this brain area and often constrains the free will to act (60). Finally, neural activity in certain brain areas can be going on for quite some times before humans become aware of their own decision $(61,62)$, suggesting that much of the processes leading to a decision are taking place at the unconscious level.
Ingestive behavior in both humans and rodents appears to become particularly resistant to cognitive controls when it is highly habitual $(63,64)$. Under normal conditions, information about possible outcomes is important for cue-induced goal-directed actions making such actions sensitive to devaluation. However, habitual behavior no longer depends on learned reward expectations and is thus largely insensitive to mechanisms of reward devaluation $(64,65)$. The neural circuits governing non-habitual behaviors are differently organized than those for habitual or automatic behaviors. Non-habitual behaviors heavily depend on the ventral striatum (nucleus accumbens) and the ventromedial prefrontal cortex, whereas habitual behaviors depend more on the dorsolateral striatum $(65,66)$. The memory storage and recall mechanisms are also different for habitual vs. non-habitual actions and behaviors. In distinction to declarative memories which require a conscious mind, procedural memories operate largely below the level of conscious awareness and storage is more distributed (67-69). As a consequence, procedural memories and the habitual ingestive behaviors they guide are relatively resistant to inhibitory cognitive control and executive functions.

\section{CONCLUSION}

Animal models have been crucial for dissecting the complex mechanisms underlying predisposition to obesity. Given that the overwhelming majority of genetic loci linked to human obesity are associated with neural functions (70), it is not surprising that the neural controls of food intake and regulation of energy balance are a main component of these mechanisms. Although functional neuroimaging in humans is also starting to make important contributions, only the more invasive approaches in rodents have been able to provide mechanistic explanations. As a result, the traditional dichotomy between homeostatic and non-homeostatic/ hedonic systems responsible for the control of appetite and regulation of body weight, although heuristically still useful, no longer adequately describes the extensive anatomical and functional interactions between the two systems. In addition, much of the output of this larger interactive system is bypassing awareness. The implications of these new insights are far reaching as they will guide not only future research but also the design of pharmacological and behavioral therapies for obesity and eating disorders.

\section{AUTHOR CONTRIBUTIONS}

$\mathrm{HM}$ and $\mathrm{CM}$ helped conceive the opinion, reviewed the literature, wrote parts of the manuscript, and edited the pre-final version of the manuscript. EQ-C and SY were involved in discussions of the original idea, reviewed parts of the literature, wrote parts of the manuscript, and edited the pre-final manuscript. $\mathrm{H}-\mathrm{RB}$ conceived the original idea for the opinion, discussed several draft versions of the manuscript with all coauthors, researched the literature, and wrote the final manuscript.

\section{FUNDING}

This work was supported by National Institutes of Health grant DK047348 (H-RB), DK092587 (HM), and DK081563 (CM). 


\section{REFERENCES}

1. Keesey RE, Powley TL. Hypothalamic regulation of body weight. Am Sci (1975) 63:558-65.

2. Keesey RE, Powley TL. Body energy homeostasis. Appetite (2008) 51:442-5. doi:10.1016/j.appet.2008.06.009

3. Brobeck JR. Hypothalamus, appetite, and obesity. Physiol Pharmacol Physicians (1963) 18:1-6.

4. Schwartz MW, Woods SC, Porte D Jr, Seeley RJ, Baskin DG. Central nervous system control of food intake. Nature (2000) 404:661-71.

5. Saper CB, Chou TC, Elmquist JK. The need to feed: homeostatic and hedonic control of eating. Neuron (2002) 36:199-211. doi:10.1016/ S0896-6273(02)00969-8

6. Balthasar N. Genetic dissection of neuronal pathways controlling energy homeostasis. Obesity (Silver Spring) (2006) 14(Suppl 5):222S-7S. doi:10.1038/ oby. 2006.313

7. Berthoud HR, Morrison C. The brain, appetite, and obesity. Annu Rev Psychol (2008) 59:55-92. doi:10.1146/annurev.psych.59.103006.093551

8. Wirtshafter D, Davis JD. Set points, settling points, and the control of body weight. Physiol Behav (1977) 19:75-8. doi:10.1016/0031-9384(77)90162-7

9. Harris RB. Role of set-point theory in regulation of body weight. FASEB J (1990) 4:3310-8.

10. Shin AC, Zheng H, Berthoud HR. An expanded view of energy homeostasis: neural integration of metabolic, cognitive, and emotional drives to eat. Physiol Behav (2009) 97:572-80. doi:10.1016/j.physbeh.2009.02.010

11. Ravussin Y, Gutman R, Diano S, Shanabrough M, Borok E, Sarman B, et al. Effects of chronic weight perturbation on energy homeostasis and brain structure in mice. Am J Physiol Regul Integr Comp Physiol (2011) 300:R1352-62. doi:10.1152/ajpregu.00429.2010

12. Speakman JR, Levitsky DA, Allison DB, Bray MS, De Castro JM, Clegg DJ. Set points, settling points and some alternative models: theoretical options to understand how genes and environments combine to regulate body adiposity. Dis Model Mech (2011) 4:733-45. doi:10.1242/dmm.008698

13. Ravussin Y, Leibel RL, Ferrante AW Jr. A missing link in body weight homeostasis: the catabolic signal of the overfed state. Cell Metab (2014) 20:565-72. doi:10.1016/j.cmet.2014.09.002

14. Morgan PJ, Ross AW, Mercer JG, Barrett P. Photoperiodic programming of body weight through the neuroendocrine hypothalamus. J Endocrinol (2003) 177:27-34. doi:10.1677/joe.0.1770027

15. Sclafani A, Springer D. Dietary obesity in adult rats: similarities to hypothalamic and human obesity syndromes. Physiol Behav (1976) 17:461-71. doi:10.1016/0031-9384(76)90109-8

16. Berridge KC. Food reward: brain substrates of wanting and liking. Neurosci Biobehav Rev (1996) 20:1-25. doi:10.1016/0149-7634(95)00033-B

17. Berridge KC. The debate over dopamine's role in reward: the case for incentive salience. Psychopharmacology (Berl) (2007) 191:391-431. doi:10.1007/ s00213-006-0578-x

18. Berridge KC, Ho CY, Richard JM, Difeliceantonio AG. The tempted brain eats: pleasure and desire circuits in obesity and eating disorders. Brain Res (2010) 1350:43-64. doi:10.1016/j.brainres.2010.04.003

19. Fulton S, Woodside B, Shizgal P. Modulation of brain reward circuitry by leptin. Science (2000) 287:125-8. doi:10.1126/science.287.5450.125

20. Fulton S, Pissios P, Manchon RP, Stiles L, Frank L, Pothos EN, et al. Leptin regulation of the mesoaccumbens dopamine pathway. Neuron (2006) 51:811-22. doi:10.1016/j.neuron.2006.09.006

21. Hommel JD, Trinko R, Sears RM, Georgescu D, Liu ZW, Gao XB, et al. Leptin receptor signaling in midbrain dopamine neurons regulates feeding. Neuron (2006) 51:801-10. doi:10.1016/j.neuron.2006.08.023

22. Domingos AI, Vaynshteyn J, Voss HU, Ren X, Gradinaru V, Zang F, et al. Leptin regulates the reward value of nutrient. Nat Neurosci (2011) 14:1562-8. doi:10.1038/nn.2977

23. Getchell TV, Kwong K, Saunders CP, Stromberg AJ, Getchell ML. Leptin regulates olfactory-mediated behavior in ob/ob mice. Physiol Behav (2006) 87:848-56. doi:10.1016/j.physbeh.2005.11.016

24. Julliard AK, Chaput MA, Apelbaum A, Aime P, Mahfouz M, Duchamp-Viret P. Changes in rat olfactory detection performance induced by orexin and leptin mimicking fasting and satiation. Behav Brain Res (2007) 183(2):123-9. doi:10.1016/j.bbr.2007.05.033
25. Yoshida R, Noguchi K, Shigemura N, Jyotaki M, Takahashi I, Margolskee $\mathrm{RF}$, et al. Leptin suppresses mouse taste cell responses to sweet compounds. Diabetes (2015) 64:3751-62. doi:10.2337/db14-1462

26. Abizaid A, Liu ZW, Andrews ZB, Shanabrough M, Borok E, Elsworth JD, et al. Ghrelin modulates the activity and synaptic input organization of midbrain dopamine neurons while promoting appetite. J Clin Invest (2006) 116:3229-39. doi:10.1172/JCI29867

27. Diano S, Farr SA, Benoit SC, Mcnay EC, Da Silva I, Horvath B, et al. Ghrelin controls hippocampal spine synapse density and memory performance. Nat Neurosci (2006) 9:381-8. doi:10.1038/nn1656

28. McNay EC. Insulin and ghrelin: peripheral hormones modulating memory and hippocampal function. Curr Opin Pharmacol (2007) 7:628-32. doi:10.1016/j. coph.2007.10.009

29. Dossat AM, Lilly N, Kay K, Williams DL. Glucagon-like peptide 1 receptors in nucleus accumbens affect food intake. J Neurosci (2011) 31:14453-7. doi:10.1523/JNEUROSCI.3262-11.2011

30. Dickson SL, Shirazi RH, Hansson C, Bergquist F, Nissbrandt H, Skibicka KP. The glucagon-like peptide 1 (GLP-1) analogue, exendin-4, decreases the rewarding value of food: a new role for mesolimbic GLP-1 receptors. J Neurosci (2012) 32:4812-20. doi:10.1523/JNEUROSCI.6326-11.2012

31. Kanoski SE, Fortin SM, Ricks KM, Grill HJ. Ghrelin signaling in the ventral hippocampus stimulates learned and motivational aspects of feeding via PI3K-Akt signaling. Biol Psychiatry (2013) 73:915-23. doi:10.1016/j. biopsych.2012.07.002

32. Irving AJ, Harvey J. Leptin regulation of hippocampal synaptic function in health and disease. Philos Trans R Soc Lond B Biol Sci (2014) 369:20130155. doi:10.1098/rstb.2013.0155

33. Kiliaan AJ, Arnoldussen IA, Gustafson DR. Adipokines: a link between obesity and dementia? Lancet Neurol (2014) 13:913-23. doi:10.1016/ S1474-4422(14)70085-7

34. van Bloemendaal L, Rg IJ, Ten Kulve JS, Barkhof F, Konrad RJ, Drent ML, et al. GLP-1 receptor activation modulates appetite- and reward-related brain areas in humans. Diabetes (2014) 63:4186-96. doi:10.2337/db14-0849

35. Farr OM, Tsoukas MA, Mantzoros CS. Leptin and the brain: influences on brain development, cognitive functioning and psychiatric disorders. Metabolism (2015) 64:114-30. doi:10.1016/j.metabol.2014.07.004

36. LockieSH, Dinan T, LawrenceAJ,Spencer SJ, AndrewsZB. Diet-induced obesity causes ghrelin resistance in reward processing tasks. Psychoneuroendocrinology (2015) 62:114-20. doi:10.1016/j.psyneuen.2015.08.004

37. Jauch-Chara K, Oltmanns KM. Obesity - a neuropsychological disease? Systematic review and neuropsychological model. Prog Neurobiol (2014) 114:84-101. doi:10.1016/j.pneurobio.2013.12.001

38. Prickett C, Brennan L, Stolwyk R. Examining the relationship between obesity and cognitive function: a systematic literature review. Obes Res Clin Pract (2015) 9:93-113. doi:10.1016/j.orcp.2014.05.001

39. Willette AA, Kapogiannis D. Does the brain shrink as the waist expands? Ageing Res Rev (2015) 20:86-97. doi:10.1016/j.arr.2014.03.007

40. Alosco ML, Gunstad J. The negative effects of obesity and poor glycemic control on cognitive function: a proposed model for possible mechanisms. Curr Diab Rep (2014) 14:495. doi:10.1007/s11892-014-0495-z

41. Castanon N, Lasselin J, Capuron L. Neuropsychiatric comorbidity in obesity: role of inflammatory processes. Front Endocrinol (2014) 5:74. doi:10.3389/ fendo.2014.00074

42. Moloney RD, Desbonnet L, Clarke G, Dinan TG, Cryan JF. The microbiome: stress, health and disease. Mamm Genome (2014) 25:49-74. doi:10.1007/ s00335-013-9488-5

43. Hargrave SL, Davidson TL, Zheng W, Kinzig KP. Western diets induce blood-brain barrier leakage and alter spatial strategies in rats. Behav Neurosci (2016) 130:123-35. doi:10.1037/bne0000110

44. Berthoud HR. Metabolic and hedonic drives in the neural control of appetite: who is the boss? Curr Opin Neurobiol (2011) 21:888-96. doi:10.1016/j. conb.2011.09.004

45. WardleJ. Conditioning processes and cue exposure in the modification of excessiveeating.AddictBehav (1990) 15:387-93.doi:10.1016/0306-4603(90)90047-2

46. Boggiano MM, Dorsey JR, Thomas JM, Murdaugh DL. The Pavlovian power of palatable food: lessons for weight-loss adherence from a new rodent model of cue-induced overeating. Int J Obes (Lond) (2009) 33:693-701. doi:10.1038/ ijo. 2009.57 
47. Weingarten HP. Conditioned cues elicit feeding in sated rats: a role for learning in meal initiation. Science (1983) 220:431-3. doi:10.1126/science.6836286

48. Petrovich GD, Setlow B, Holland PC, Gallagher M. Amygdalo-hypothalamic circuit allows learned cues to override satiety and promote eating. J Neurosci (2002) 22:8748-53.

49. Petrovich GD, Ross CA, Holland PC, Gallagher M. Medial prefrontal cortex is necessary for an appetitive contextual conditioned stimulus to promote eating in sated rats. J Neurosci (2007) 27:6436-41. doi:10.1523/ JNEUROSCI.5001-06.2007

50. Betley JN, Xu S, Cao ZF, Gong R, Magnus CJ, Yu Y, et al. Neurons for hunger and thirst transmit a negative-valence teaching signal. Nature (2015) 521:180-5. doi:10.1038/nature14416

51. Chen Y, Lin YC, Kuo TW, Knight ZA. Sensory detection of food rapidly modulates arcuate feeding circuits. Cell (2015) 160:829-41. doi:10.1016/j. cell.2015.01.033

52. DeFalco J, Tomishima M, Liu H, Zhao C, Cai X, Marth JD, et al. Virus-assisted mapping of neural inputs to a feeding center in the hypothalamus. Science (2001) 291:2608-13. doi:10.1126/science.1056602

53. Medic N, Ziauddeen H, Vestergaard MD, Henning E, Schultz W, Farooqi IS, et al. Dopamine modulates the neural representation of subjective value of food in hungry subjects. JNeurosci (2014) 34:16856-64. doi:10.1523/ JNEUROSCI.2051-14.2014

54. Aarts H, Custers R, Marien H. Preparing and motivating behavior outside of awareness. Science (2008) 319:1639. doi:10.1126/science.1150432

55. Custers R, Aarts H. The unconscious will: how the pursuit of goals operates outside of conscious awareness. Science (2010) 329:47-50. doi:10.1126/ science. 1188595

56. Ziauddeen H, Subramaniam N, Gaillard R, Burke LK, Farooqi IS, Fletcher PC. Food images engage subliminal motivation to seek food. Int J Obes (Lond) (2012) 36:1245-7. doi:10.1038/ijo.2011.239

57. Pessiglione M, Petrovic P, Daunizeau J, Palminteri S, Dolan RJ, Frith CD. Subliminal instrumental conditioning demonstrated in the human brain. Neuron (2008) 59:561-7. doi:10.1016/j.neuron.2008.07.005

58. Hare TA, Camerer CF, Rangel A. Self-control in decision-making involves modulation of the vmPFC valuation system. Science (2009) 324:646-8. doi:10.1126/science. 1168450

59. Hare TA, Schultz W, Camerer CF, O'Doherty JP, Rangel A. Transformation of stimulus value signals into motor commands during simple choice. Proc Natl Acad Sci U S A (2011) 108:18120-5. doi:10.1073/pnas.1109322108

60. Schultz W. Neuronal reward and decision signals: from theories to data. Physiol Rev (2015) 95:853-951. doi:10.1152/physrev.00023.2014

61. Soon CS, Brass M, Heinze HJ, Haynes JD. Unconscious determinants of free decisions in the human brain. Nat Neurosci (2008) 11:543-5. doi:10.1038/nn.2112
62. Bode S, Murawski C, Soon CS, Bode P, Stahl J, Smith PL. Demystifying "free will": the role of contextual information and evidence accumulation for predictive brain activity. Neurosci Biobehav Rev (2014) 47:636-45. doi:10.1016/j. neubiorev.2014.10.017

63. de Jong JW, Meijboom KE, Vanderschuren LJ, Adan RA. Low control over palatable food intake in rats is associated with habitual behavior and relapse vulnerability: individual differences. PLoS One (2013) 8:e74645. doi:10.1371/ journal.pone.0074645

64. Horstmann A, Dietrich A, Mathar D, Possel M, Villringer A, Neumann J. Slave to habit? Obesity is associated with decreased behavioural sensitivity to reward devaluation. Appetite (2015) 87:175-83. doi:10.1016/j.appet.2014.12.212

65. McNamee D, Liljeholm M, Zika O, O'Doherty JP. Characterizing the associative content of brain structures involved in habitual and goal-directed actions in humans: a multivariate FMRI study. J Neurosci (2015) 35:3764-71. doi:10.1523/JNEUROSCI.4677-14.2015

66. Furlong TM, Jayaweera HK, Balleine BW, Corbit LH. Binge-like consumption of a palatable food accelerates habitual control of behavior and is dependent on activation of the dorsolateral striatum. J Neurosci (2014) 34:5012-22. doi:10.1523/JNEUROSCI.3707-13.2014

67. Pittenger C, Fasano S, Mazzocchi-Jones D, Dunnett SB, Kandel ER, Brambilla R. Impaired bidirectional synaptic plasticity and procedural memory formation in striatum-specific cAMP response element-binding protein-deficient mice. JNeurosci (2006) 26:2808-13. doi:10.1523/ JNEUROSCI.5406-05.2006

68. Kandel ER, Dudai Y, Mayford MR. The molecular and systems biology of memory. Cell (2014) 157:163-86. doi:10.1016/j.cell.2014.03.001

69. Squire LR, Dede AJ. Conscious and unconscious memory systems. Cold Spring Harb Perspect Biol (2015) 7:a021667. doi:10.1101/cshperspect.a021667

70. Locke AE, Kahali B, Berndt SI, Justice AE, Pers TH, Day FR, et al. Genetic studies of body mass index yield new insights for obesity biology. Nature (2015) 518:197-206. doi:10.1038/nature14177

Conflict of Interest Statement: The authors declare that the research was conducted in the absence of any commercial or financial relationships that could be construed as a potential conflict of interest.

Copyright (c) 2016 Münzberg, Qualls-Creekmore, Yu, Morrison and Berthoud. This is an open-access article distributed under the terms of the Creative Commons Attribution License (CC BY). The use, distribution or reproduction in other forums is permitted, provided the original author(s) or licensor are credited and that the original publication in this journal is cited, in accordance with accepted academic practice. No use, distribution or reproduction is permitted which does not comply with these terms. 